\title{
Influência da Taxa de Câmbio e da Renda Mundial nas Exportações do Estado do Espírito Santo
}

\section{Influence of Exchange Rate and World income on Exports of Espírito Santo State}

\author{
Edson Zambon Monte*
}

\begin{abstract}
Resumo: Este trabalho objetiva estimar os impactos de choques na taxa de câmbio e na renda mundial sobre as exportações do Espírito Santo, utilizando a metodologia VAR/VECM. Os resultados demonstraram que: a) as variáveis são cointegradas, sendo que na equação de longo prazo a renda mundial afetou significantemente as exportações, enquanto a taxa de câmbio apresentou sinal negativo e foi não significativa; b) as estimativas de curto prazo do vetor de cointegração revelaram que, para a variável exportações, os desequilíbrios de curto prazo são corrigidos de forma relativamente rápida, o que não acontece para as variáveis taxa de câmbio e renda mundial; c) nas funções impulso-reposta verificou-se que um choque na taxa de câmbio tem efeitos negativos sobre as exportações em quase todos os períodos após o choque, contrário a teoria econômica, e a renda mundial afeta positivamente as exportações; e, d) a análise de decomposição da variância demonstrou que a renda mundial é relativamente mais importante que a taxa de câmbio na explicação da variância do erro de previsão das exportações.
\end{abstract}

Palavras-chave: Exportações. VAR/VECM. Espírito Santo.

Abstract: The objective of this paper was to estimate the impacts of shocks on exchange rate and world income, in the exports of Espírito Santo State, using the methodology VAR/VECM. The results showed that: a) variables are cointegrated and world income affected significantly the exports in the long-term, while the exchange rate had a negative sign and was not significant; b) estimates of short-term cointegrating vector revealed that for the variable exports of short-term imbalances are corrected quickly. It doesn't happen for variables exchange rate and world income; c) the impulse-response functions show that a shock in the exchange rate has a negative impact on exports in almost all periods after the shock (contrary to economic theory) and world income affects positively exports; and, d) the decomposition analysis of variance showed that the world income is relatively more important that the exchange rate in explaining the forecast error variance of exports.

Keywords: Exports. VAR/VECM. Espírito Santo State.

JEL Classification: C32; F11; F17.

Doutorando em Engenharia Ambiental pela Universidade Federal do Espírito Santo (UFES). Professor do Departamento de Ciências Econômicas da UFES. E-mail: edsonzambon@yahoo. com.br 


\section{1 lntrodução}

A experiência exportadora do estado do Espírito Santo começou com a economia cafeeira, advinda do Rio de Janeiro, em meados do século XIX. Esta, num primeiro momento, formou-se nos moldes da monocultura escravista latifundiária que logo cedeu espaço para uma estrutura de pequeno produtor familiar. A importância dessa atividade, outrora, fora de ocupar e integrar o estado, sendo o motor do desenvolvimento de muitas cidades. A partir da década de 1970, em adição as exportações de commodities agrícolas, surgiram os grandes projetos industriais. A ampliação e criação de portos, aliadas à construção de grandes indústrias (Companhia Vale do Rio Doce e Companhia Siderúrgica Tubarão), ${ }^{1}$ dinamizaram o perfil exportador da economia capixaba.

Nesse contexto, o Espírito Santo possui um conjunto de características que proporcionam um potencial exportador destacável. Seu vasto litoral com localização privilegiada na região Sudeste e sua infraestrutura de rodovias e portos advinda em grande parte da economia cafeeira e, posteriormente, dos grandes projetos, garantem um cenário favorável e com grande capacidade de ampliação.

O estado figura em sétimo lugar ${ }^{2}$ no ranking dos maiores estados exportadores do Brasil. Os portos capixabas estão entre os principais portos do país, merecendo destaque o porto de Vitória que, em 2011, foi o segundo mais importante no quesito exportação/US\$ FOB (Free on Board), escoando aproximadamente $27 \%$ da carga marítima brasileira. Além disso, o Espírito Santo sobressai no cenário nacional como um estado com um dos maiores percentuais de abertura ao comércio exterior, em média de 48\% (MAGALHÃES; TOSCANO, 2009). Em relação à participação das exportações no nível de atividade econômica, nos últimos anos as exportações têm representado, em média, cerca de $27 \%$ do Produto Interno Bruto (PIB) capixaba.

A Tabela 1 apresenta a evolução das exportações do Espírito Santo, no período de 2000 a 2011 . Observa-se que no ano de 2009 ocorreu uma forte retração das exportações, o que pode ser explicado pelos reflexos da crise financeira do subprime, que afetou as expectativas e o crédito em nível mundial. No entanto, verifica-se que, em 2010, o valor das exportações atingiu níveis superiores aos de 2008. Levando-se em consideração o período como um todo, as exportações cresceram, aproximadamente, 543,06\%. A elevação média anual foi de 16,31\%. Destaca-se que a pauta de exportações estatual é concentrada e pouco diversificada, com destaque para as commodities, principalmente o minério de ferro e o aço. Os principais destinos dessas exportações no ano de 2011 foram Estados Unidos, China, Holanda, Coreia do Sul, Argentina e Arábia Saudita.

\footnotetext{
1 Hoje, Vale S.A. e Arcelor Mittal Tubarão S.A., respectivamente.

2 Este ranking leva em consideração o ano de 2011, o ano de 2010 e o acumulado de 2000 até 2011. Nas três situações, o estado fica na sétima posição.
} 
Tabela 1 - Evolução anual das exportações do Espírito Santo

\begin{tabular}{ccc}
\hline Ano & Exportação (R\$ 1.000 FOB) & Var (\%) \\
\hline 2000 & $2.791 .322,24$ & - \\
2001 & $2.429 .260,56$ & $-12,97$ \\
2002 & $2.596 .759,02$ & 6,90 \\
2003 & $3.534 .563,92$ & 36,11 \\
2004 & $4.054 .552,01$ & 14,71 \\
2005 & $5.591 .454,20$ & 37,91 \\
2006 & $6.720 .018,50$ & 20,18 \\
2007 & $6.871 .954,87$ & 2,26 \\
2008 & $10.099 .372,31$ & 46,97 \\
2009 & $6.510 .240,95$ & $-35,54$ \\
2010 & $12.271 .163,10$ & 88,49 \\
2011 & $15.158 .502,60$ & 23,53 \\
\hline
\end{tabular}

Fonte: Elaboração própria a partir de Brasil (2012b).

Dessa forma, considerando que a) o Espírito Santo é visto como um estado com vocação para o comércio exterior; b) que o estado possui um dos maiores graus de abertura comercial do Brasil, escoando parte significativa das exportações brasileiras; e, c) que o fluxo de exportações é importante para o desempenho capixaba, tanto na geração de emprego e renda, como em termos de participação do PIB, este artigo objetiva verificar a sensibilidade das exportações do estado do Espírito Santo a choques na taxa de câmbio e na renda mundial.

\section{Revisão de Literatura Empírica}

Esta seção tem a finalidade de demonstrar alguns trabalhos que vêm sendo realizados nos últimos anos no Brasil, analisando as exportações nacionais ou regionais, seja no agregado, seja por produtos, dando ênfase à utilização das metodologias vetorial autorregressiva (VAR) e vetor de correção de erros (VECM), utilizadas nesta pesquisa.

Castro e Cavalcanti (1998), utilizando a metodologia VECM, fizeram estimações de equações de exportação totais e desagregadas (produtos manufaturados, semimanufaturados e básicos) para o Brasil, no período de 1955 a 1995. Os autores incluíram no modelo as seguintes variáveis explicativas: a taxa de câmbio real, uma proxy para o nível de renda mundial e um indicador do nível de renda doméstico. Os resultados revelaram elasticidades renda e preço significantes. 
Cavalcanti e Ribeiro (1998) analisaram o desempenho das exportações brasileiras no período de 1977 a 1996, com destaque para os anos de 1990. Como método econométrico, os autores adotaram, inicialmente, um modelo VAR para as exportações e, a partir de testes de cointegração e exogeneidade, estimaram uma equação autorregressiva com defasagens distribuídas (ADD). Os resultados mostraram que, para os produtos básicos, semimanufaturados e manufaturados, as exportações dependem, principalmente, das condições de demanda do mercado internacional, a saber: renda mundial e preços dos produtos exportados relativamente aos bens substitutos. Para os produtos industriais as exportações são fortemente afetadas por fatores ligados a oferta: taxa de rentabilidade e, possivelmente, capacidade produtiva. Além disso, as exportações de produtos industrializados são influenciadas pelo nível de comércio externo.

Castro e Rossi Júnior (2000) estimaram equações para o valor exportado e o preço das principais commodities brasileiras, a saber: café, açúcar, soja, minério de ferro, carne bovina, alumínio, cacau, suco de laranja e fumo. Como metodologia, os autores adotaram os modelos VAR irrestritos e os modelos em diferenças restritos. Nesse contexto, os autores testaram a inclusão de variáveis exógenas no modelo e compararam a capacidade preditiva do modelo restrito à do VAR irrestrito.

Os resultados sugeriram que, somente no caso do café e do alumínio, as exportações brasileiras defasadas influenciaram o preço internacional. Para as outras commodities, as exportações brasileiras não apresentaram causalidade com os preços internacionais. Além disso, os autores verificaram que os preços defasados do café foram altamente significativos na equação do valor exportado; as importações mundiais são significativas apenas na quinta e na sexta defasagens; a variável Libor apresentou efeito contemporâneo positivo; e, o câmbio real efetivo tem um efeito negativo bastante defasado.

Silva e Maia (2003) analisaram os efeitos da renda externa, da taxa de câmbio real efetiva e do preço de exportação do café em grãos sobre as exportações brasileiras de café, no período de 1961 a 2001. Os autores adotaram o modelo VAR. No que se refere aos resultados, estes revelaram que: a) o valor das exportações de café foi mais impactado pelos choques no preço do café em grãos e na renda externa, do que pelos choques na taxa de câmbio real; b) inovações na renda externa tiveram efeitos positivos nas exportações de café a curto prazo; c) choques no preço de exportação do café em grãos acarretaram aumentos nas exportações de café nos primeiros dois anos após os choques; e, d) o efeito de um choque na taxa de câmbio nas exportações de café revelou-se positivo no primeiro ano e negativo no segundo ano.

Maia (2003) examinou os impactos da taxa de câmbio e da taxa de juros sobre as exportações de produtos agrícolas brasileiros em dois períodos distintos: a) de janeiro de 1980 até dezembro de 1990; e, b) de janeiro de 1990 até dezembro 
de 2001. O autor utilizou como modelo teórico a abordagem de microeconomia aberta a partir do modelo Mundell-Fleming. A metodologia empírica adotada foi o modelo VAR, com causalidades contemporâneas.

Quanto aos resultados, a taxa de câmbio apresentou-se significativa na determinação das exportações agrícolas brasileiras, tanto no curto prazo como no longo prazo. Ressalta-se que, na análise contemporânea (curto prazo), a influência da taxa de câmbio diminui do período de 1980 a 1990, para o período de 1990 a 2001. No primeiro período, uma elevação da taxa de câmbio representava $45 \%$ das variações das exportações; no segundo período, esse valor passou para 39\%, perfazendo uma redução de seis pontos percentuais. A taxa de juros também teve efeito sobre as exportações agrícolas brasileiras, tanto no curto prazo como no longo prazo.

Alves e Bachi (2004) estimaram uma função de oferta de exportação brasileira de açúcar, para o período de outubro de 1995 a dezembro de 2002. Como procedimento empírico, os autores utilizaram a metodologia VAR. Os resultados demonstram que o preço e a renda doméstica, variáveis que refletem a situação do mercado interno, têm grande relevância na determinação das exportações brasileiras de açúcar, sendo o efeito defasado (subsequente ao choque) dessas variáveis sobre o quantum exportado bastante agressivo. Também, verificou-se que as exportações brasileiras de açúcar elevam-se à medida que a moeda nacional desvaloriza-se perante o dólar norte-americano. Destaca-se que o efeito da taxa de câmbio sobre o quantum exportado é mais expressivo após três meses de choque. No que se refere ao preço das exportações, este apresentou menor elasticidade quando comparado às variáveis de mercado interno, porém também teve algum grau de influência sobre o quantum de açúcar exportado pelo Brasil.

Silva e Bachi (2005) examinaram as equações de exportação para o açúcar bruto brasileiro, com a finalidade de identificar os determinantes do desempenho exportador dessa commodity. A metodologia utilizada foi a VAR/VECM, sendo consideradas as propriedades de integração e cointegração das séries utilizadas. Os resultados demonstraram que as exportações de açúcar bruto dependem essencialmente das condições do mercado externo, nesse caso, representadas pelas variáveis renda da Rússia e taxa de câmbio, e do preço doméstico. Esta última variável não teve efeito contemporâneo significativo sobre o quantum exportado, porém seu efeito aumentou ao longo do tempo.

Morais e Barbosa (2006) modelaram as equações de oferta e demanda por exportações de calçados brasileiros no período entre o primeiro trimestre de 1985 e o primeiro trimestre de 2003. Para isso, os autores utilizaram a metodologia de Johansen para cointegração. Em relação aos resultados estimados, os autores salientam que, para a equação de oferta, os impactos de uma variação da taxa de câmbio têm grande relevância sobre o quantum exportado de calçados no lon- 
go prazo. Também, para a equação de oferta de exportação, verificou-se que os impactos de variações nos preços ocorrem no longo prazo. Para a equação de demanda, observou-se uma elasticidade preço negativa, com maiores efeitos no curto prazo. A elasticidade renda estimada mostrou-se positiva, com seus impactos acorrendo no curto prazo.

Sapienza (2007) buscou estimar as elasticidades das equações da oferta de exportação e da demanda de importação para o Brasil no período de 1980 a 2006, utilizando dados trimestrais. Na análise empírica, foram utilizadas as técnicas de cointegração multivariada de Johansen Juselius e o VECM. Os resultados demonstraram a existência de uma relação de longo prazo (cointegração) entre volume exportado brasileiro e as seguintes variáveis: taxa de câmbio real, volume das exportações mundiais e índice de preços internacionais de commodities.

O objetivo do estudo de Padrão, Profeta e Gomes (2010) foi verificar os determinantes da oferta de exportação mineira de café no período de julho de 1999 a dezembro de 2008, tomando com base o modelo-padrão da teoria do comércio internacional. Como metodologia econométrica, os autores adotaram o VECM, analisando as funções de impulso-resposta e realizando a decomposição da variância. Referente aos resultados, estes apontaram que a quantidade exportada de café é afetada, principalmente, pelo preço externo e pela taxa efetiva real de câmbio.

\section{Modelo Econômico}

São vários os trabalhos existentes sobre o comércio internacional, alguns analisando as exportações no agregado, outros analisando a comercialização de produtos de forma individual. Entre os estudos que analisam funções de exportação, pode-se citar Zini Júnior (1988), Castro e Cavalcanti (1998), Cavalcanti e Ribeiro (1998), Carvalho e De Negri (2000), Miranda (2001), Barros, Bacchi e Burnquist (2002), Alves e Bachi (2004), Silva e Bachi (2005) e Moraes e Barbosa (2006), etc.

Nesta pesquisa, adotou-se, em parte, o modelo de exportação proposto por Castro e Cavalcanti (1998). Nesse modelo, a equação de exportação pode ser representada por:

$$
x=e+y
$$

em que: $x$ representa o valor real das exportações; $e$, taxa de câmbio real; e, $y$, importações mundiais totais, em valor real, como proxy da renda mundial. Espera-se que choques positivos na taxa de câmbio e na renda mundial ocasionem impactos positivos nas exportações capixabas. 


\section{Vetor Autorregressivo (VAR) e Vetor de Correção de Erros (VECM) ${ }^{3}$}

Pode-se expressar um modelo VAR ${ }^{4}$ de ordem $p$ em função de um vetor com $n$ variáveis endógenas, $X_{t}$, sendo que estas se conectam por meio de uma matriz $A$, da seguinte forma:

$$
A X_{t}=B_{0}+\sum_{i=1}^{p} B_{i} X_{t-i}+B \varepsilon_{t},
$$

em que: $A$ é uma matriz $n \times n$ que define as restrições contemporâneas entre as variáveis que constituem o vetor $n \times 1, X_{t} ; B_{0}$, vetor de constantes $n \times 1 ; B_{t}$, matrizes $n \times n ; B$, matriz diagonal $n \times n$ de desvios-padrão; e, $\varepsilon_{\mathrm{t}}$, vetor $n \times 1$ de perturbações aleatórias não correlacionadas entre si contemporânea ou temporalmente, isto é:

$$
\varepsilon_{\mathrm{t}} \sim \text { i.i.d }\left(0 ; I_{n}\right)
$$

A equação 2 expressa às relações entre as variáveis endógenas, geralmente advindas de um modelo econômico teoricamente estruturado, e é denominada de forma estrutural. No entanto, devido à endogeneidade das variáveis do VAR, o modelo é normalmente estimado em sua forma reduzida, dada por:

$$
X_{t}=A^{-1} B_{0}+\sum_{i=1}^{p} A^{-1} B_{i} X_{t-i}+A^{-1} B \varepsilon_{t}=\Phi_{0}+\sum_{i=1}^{p} \Phi_{i} X_{t-i}+e_{t},
$$

em que: $\Phi_{i}=A^{-1} B_{i}, i=0,1,2, \ldots, p$ e $B \varepsilon_{t}=A e_{t}$.

A metodologia VAR pode ser estimada por meio do método de Mínimos Quadrados Ordinários (MQO), levando-se em conta, principalmente, a interação entre as variáveis do sistema considerado. Entre as suas principais vantagens na análise econométrica estão a obtenção das funções de impulso-resposta (FRI) e a decomposição da variância (DV).

Vale lembrar que, caso as variáveis estudadas sejam cointegradas, o modelo original pode ser descrito na forma de um VECM. Engle e Granger (1987) apresentaram a cointegração da seguinte forma: a) os componentes de um vetor $X_{t}, n \times$ 1 , são ditos serem cointegrados de ordem $(d, b)$, denotados por $X_{t} \sim C I(d, b)$, se: (i) todos os componentes de $X_{t}$ são $\left.I(d) ; e, b\right)$ existe pelo um vetor não nulo $\beta$, tal que $u_{t}=X_{t}^{\prime} \beta \sim(d-b), b>0$. O vetor $\beta$ é chamado de vetor de cointegração.

Cabe dizer que a definição de cointegração de Campbell e Perron (1991) é mais abrangente, não impondo a restrição de mesma ordem de integração para a existência de cointegração. Segundo esses autores, basta que ocorra a segunda condição descrita anteriormente para que os elementos de um vetor $X_{t}$ sejam

3 Metodologia desenvolvida inicialmente por Sims (1980).

4 A metodologia VAR descrita aqui está baseada em Bueno (2011, cap. 6). 
cointegrados. Nesse caso, deve haver pelo menos duas variáveis integradas de mesma ordem na ordem máxima de integração entre todas as variáveis, para que haja cointegração. ${ }^{5}$ Ainda, Hansen e Juselius (1995) descrevem que uma condição necessária para encontrar uma relação de cointegração entre variáveis não estacionárias exige que somente duas das variáveis do modelo sejam integradas de ordem um I(1).

Nesse contexto, tomando-se duas variáveis cointegradas, $y_{t}$ e $z_{t}$, um VECM simples pode ser representado por:

$$
\begin{aligned}
& \Delta y_{t}=\alpha_{1} \hat{u}_{t-1}+\sum_{j=1}^{p-1} \lambda_{11, j+1} \Delta y_{t-j}+\sum_{j=1}^{p-1} \lambda_{12, j+1} \Delta z_{t-j}+e_{y t}, \\
& \Delta z_{t}=\alpha_{2} \hat{u}_{t-1}+\sum_{j=1}^{p-1} \lambda_{21, j+1} \Delta y_{t-j}+\sum_{j=1}^{p-1} \lambda_{22, j+1} \Delta z_{t-j}+e_{z t} .
\end{aligned}
$$

Em relação ao VAR original, as diferenças serão percebidas na magnitude dos coeficientes estimados. No entanto, o mais importante é notar que não adicionar os resíduos de cointegração no modelo levaria ao problema de omissão de variáveis explicativas, resultando em estimadas viesadas dos parâmetros.

A forma mais geral de um VECM é dada por:

$$
\Delta X_{t}=\Phi X_{t-1}+\sum_{i=1}^{p-1} \Lambda_{i} \Delta X_{t-i}+e_{t}
$$

em que: $X_{t}$ é um vetor $n \times 1$ de variáveis endógenas; e, $\Lambda_{i}=-\sum_{j=1+i}^{p} \Phi_{j} ; i=1,2, \ldots, p-1$.

Havendo raiz unitária, significa que $\Phi(I)=0$, de modo que $\Phi=\alpha \beta$. Nesse caso, $\beta$ é a matriz que tem $r$ vetores de cointegração e $\alpha$ é a matriz de ajustamento, com $r$ vetores de ajustamento. O modelo de correção de erros é assim chamado porque a variação de $X_{t}$ é explicada por dois componentes: os fatores de curto prazo, $\sum_{i=1}^{p-1} \Lambda_{i} \Delta X_{t-i}$; e, a relação de longo prazo dada entre as coordenadas do vetor de variáveis endógenas, $\Phi X_{t-1}$, caso ocorra cointegração.

Um dos métodos para verificar a existência de cointegração é o teste de Johansen (1988), que é uma alternativa ao teste de Engle e Granger (1987). Johansen propõe definir o posto da matriz $\Phi$ da equação,

$$
\Delta X_{t}=\Phi X_{t-1}+\sum_{i=1}^{p-1} \Lambda_{i} \Delta X_{t-i}+e_{t}
$$

$5 \quad$ Para mais detalhes, verificar Bueno (2011, cap. 7). 
e, dessa forma, estimar os vetores de cointegração $\beta$. De maneira a definir o posto da matriz $\Phi$, Johansen sugeriu dois testes baseados em uma estimação de máxima verossimilhança com restrição.

Tem-se que $\Phi$ é uma matriz $n \times n$, e seu posto é dado por $r<n$, caso haja cointegração. Sendo o posto dessa matriz igual a $n$, as variáveis endógenas são todas estacionárias. Se o posto da matriz for nulo $(\Phi=0)$, não há cointegração e as variáveis são não estacionárias. Como o determinante de uma matriz é o produto de seus autovalores, e considerando que o posto de $\Phi$ está entre zero e $n$, pode-se dizer que $\Phi$ terá $r$ autovalores diferentes de zero e $n-r$ autovalores iguais a zero. A ideia, então, é encontrar esses autovalores.

Variáveis determinísticas podem interferir nos valores críticos do modelo. Logo, incluem-se essas variáveis em $X_{t}$, no nível de vetor de cointegração, de modo que,

$$
X_{t}=\Phi_{1} X_{t-1}+\Phi_{2} X_{t-2}+\ldots+\Phi_{p} X_{t-p}+\delta^{\prime} d_{t}+e_{t}
$$

em que: $\delta=[1, t]$ é um vetor com variáveis determinísticas, tais como dummies sazonais, entre outras; e, $\delta$, matriz de coeficientes de dimensão compatível com $d_{t}$, que, nesse caso, tem dimensão dada por $2 \times n$.

$\mathrm{Na}$ forma de VECM, o modelo anterior fica da seguinte forma:

$$
\Delta X_{t}=\Phi X_{t-1}+\sum_{i=1}^{p-1} \Lambda_{i} \Delta X_{t-i}+\delta^{\prime} d_{t}+e_{t}
$$

Para encontrar os autovalores da matriz $\Phi$, maximiza-se a equação $10 \mathrm{com}$ restrições sobre a matriz de covariância. Os autovalores são, então, ordenados do maior para o menor, $\lambda_{1}>\lambda_{2} \ldots>\lambda_{n}$, sendo que cada um está associado a um autovetor que será associado aos vetores de cointegração contidos em $\beta$.

Nesse contexto, o primeiro teste proposto por Johansen é o teste de traço. A hipótese nula é de existência de $r^{*}$ vetores de cointegração. A hipótese alternativa é de $r>r^{*}$ vetores. De maneira formal, tem-se:

$$
\begin{aligned}
& H_{0}: r=r^{*} \\
& H_{1}: r>r^{*}
\end{aligned}
$$


A estatística de teste é dada por: 6

$$
\lambda_{t r}(r)=-T \sum_{i=r+1}^{n} \ln \left(1-\hat{\lambda}_{i}\right)
$$

O posto da matriz $\Phi$ equivale ao número de suas raízes características que são diferentes de zero. Caso não haja cointegração, os autovalores serão próximos de zero, demonstrando não estacionariedade ou instabilidade da matriz $\Phi$, e $\ln \left(1-\hat{\lambda}_{i}\right) \rightarrow 0$. Isso implica em pequenos valores para a estatística de traço, estabelecendo a não rejeição da hipótese nula. Se o $\lambda_{i}$ é significantemente diferente de zero, então $\ln \left(1-\hat{\lambda}_{i}\right)$ será negativo. Logo, o valor da estatística de traço será alto, implicando na rejeição da hipótese.

O teste é crescente, isto é, inicia-se com a soma de $n$ "logs" de 1 menos o autovalor, considerando, primeiramente, $r^{*}=0$. A rejeição da hipótese nula implica a existência de mais de um vetor de cointegração. Continuando, parte-se para a soma dos $n-1$ "logs" de 1 menos os autovalores correspondentes, até o momento em que a hipótese nula não for mais rejeitada. Mackinnon, Haung e Michelis (1999) apresentam a tabela mais recente deste teste.

O segundo teste é denominado de teste de autovalor e tende apresentar resultados mais robustos que o teste de traço. A hipótese nula estabelece a existência de $r^{*}$ vetores de cointegração. Já a hipótese alternativa é de que existem $r^{*}+1$ vetores de cointegração. Formalmente,

$$
\begin{aligned}
& H_{0}: r=r^{*} \\
& H_{1}: r=r^{*}+1
\end{aligned}
$$

A estatística de teste é representada pela equação 14:

$$
L R(r)=-T \ln \left(1-\hat{\lambda}_{r+1}\right) .
$$

Em síntese, o teste de autovalor verifica qual o máximo autovalor significativo que da origem a um vetor de cointegração. O teste também é crescente e rejeitar a hipótese nula significa que existe mais de um vetor de cointegração. Caso a hipótese nula não seja rejeitada, há $r^{*}$ vetores de cointegração. Vale lembrar que na realização do teste é preciso estabelecer cuidadosamente o número de defasagens. Além disso, o modelo deve ser determinado com cautela, levando

6 Os autovalores são normalizados para que sempre sejam menores do que um. Logo, o ln será negativo. Isso é possível devido a não identificabilidade da matriz $\Phi$. 
em conta a existência de constante e tendência no nível do vetor $X_{t}$ e no vetor de cointegração.

\section{Resultados e Discussões}

Esta seção está dividida da seguinte forma: na primeira parte são apresentadas as variáveis; na segunda, as estatísticas descritivas e a análise gráfica das séries de dados; na terceira, apresentam-se os testes de raiz unitária; e, na quarta, encontram-se os testes de cointegração. Por fim, faz-se a análise do VECM.

\subsection{Apresentação das Variáveis}

Este estudo compreende o período entre janeiro de 2000 e dezembro de 2011. A Tabela 2 sintetiza as variáveis utilizadas no estudo. Os dados referentes ao valor das exportações capixabas (US\$ FOB) ${ }^{7}$ e à quantidade exportada $(\mathrm{kg})$ foram adquiridos junto à Secretaria de Comércio Exterior (Secex), do Ministério do Desenvolvimento, Indústria e Comércio Exterior (MDIC) brasileiro, na base de dados Aliceweb. O valor das exportações foi deflacionado pelo Índice de Preços por Atacado - IPA (base janeiro de 2003), dos Estados Unidos, divulgados pelo Fundo Monetário Internacional (FMI).

A taxa de câmbio efetiva real foi coletada junto à Fundação Getúlio Vargas (FGV/FGVDADOS). Utilizaram-se as importações mundiais como proxy para a renda mundial, disponíveis no site do Ipeadata, tendo como fonte original o FMI. O valor das importações mundiais foi deflacionado pelo IPA dos Estados Unidos.

$7 \quad$ A série de exportações foi expressa em termos de valores (US\$ FOB), que segundo Castro e Cavalcanti (1998), representa uma grande diferença em relação à maioria dos estudos que trabalham com funções de exportações e importações, uma vez que eles tendem a utilizar o quantum exportado, sendo este preferível do ponto de vista teórico. Entretanto, os dados em valor possuem a vantagem de fornecerem os resultados aplicáveis diretamente à análise da balança comercial de um país ou região. 
Tabela 2 - Variáveis, unidades, siglas e fontes ${ }^{8}$

\begin{tabular}{|c|c|c|c|}
\hline Variável & Unidade & Sigla & Fonte \\
\hline Valor das exportações & $\begin{array}{l}\text { US\$ milhões } \\
\text { FOB }\end{array}$ & EXPES & MDIC/Secex \\
\hline $\begin{array}{l}\text { Taxa de câmbio - efetiva real - IPA- } \\
\text { OG }\end{array}$ & Índice & TXCAM & $\begin{array}{l}\text { FGVDA- } \\
\text { DOS }\end{array}$ \\
\hline $\begin{array}{l}\text { Renda mundial - Utilizaram-se como } \\
\text { proxy as importações mundiais }\end{array}$ & $\begin{array}{l}\text { US\$ bilhões } \\
\text { CIF }\end{array}$ & RMUND & Ipeadata \\
\hline
\end{tabular}

Fonte: Elaboração própria.

Nota: FOB: Free on board; e CIF: Cost, Insurance and Freight.

\subsection{Estatísticas Descritivas e Análise Gráfica das Variáveis}

A Tabela 3 apresenta as estatísticas descritivas das variáveis e o Gráfico 1 a evolução de cada série de dados ao longo do período de análise. Em relação à análise gráfica, merece destaque o fato de que, no período da crise do subprime (iniciada nos Estados Unidos), as variáveis EXPES e RMUND apresentaram forte queda, começando a se recuperarem no final no ano de 2010. Nota-se um comportamento semelhante dessas variáveis. Outro ponto importante refere-se à evolução das variáveis EXPES e TXCAM. Verifica-se que essas duas variáveis, contrário à teoria econômica, seguiram tendências distintas no período de análise. Enquanto as exportações cresceram no período como um todo cerca de 1,02\% ao mês, a taxa de câmbio reduziu-se, apresentando uma queda de 0,07\% ao mês.

Tabela 3 - Estatísticas descritivas das variáveis

\begin{tabular}{lrrrrrr}
\hline Variável & Obs. & Média & Mediana & $\begin{array}{l}\text { Desvio- } \\
\text { padrão }\end{array}$ & Máximo & Mínimo \\
\hline EXPES & 144 & 410,26 & 365,15 & 201,80 & 987,25 & 126,57 \\
TXCAM & 144 & 79,59 & 74,03 & 21,43 & 136,18 & 49,03 \\
RMUND & 144 & 944,81 & 926,13 & 338,08 & 1590,16 & 468,30 \\
\hline
\end{tabular}

Fonte: Elaboração própria a partir dos dados da pesquisa.

Nota: EXPES: US \$ milhões FOB; TXCAM: índice; PREXT: US\$ $/ k g ;$ RMUND: US\$ bilhões CIF.

$8 \quad$ Tentou-se a estimação com uma variável exógena (dummy) para captar o efeito da crise do subprime. No entanto, como tal variável foi não significativa estatisticamente, e objetivando a parcimônia do modelo, optou-se por retirá-la. 
Gráfico 1 - Evolução das variáveis no período de janeiro de 2000 a dezembro de 2011

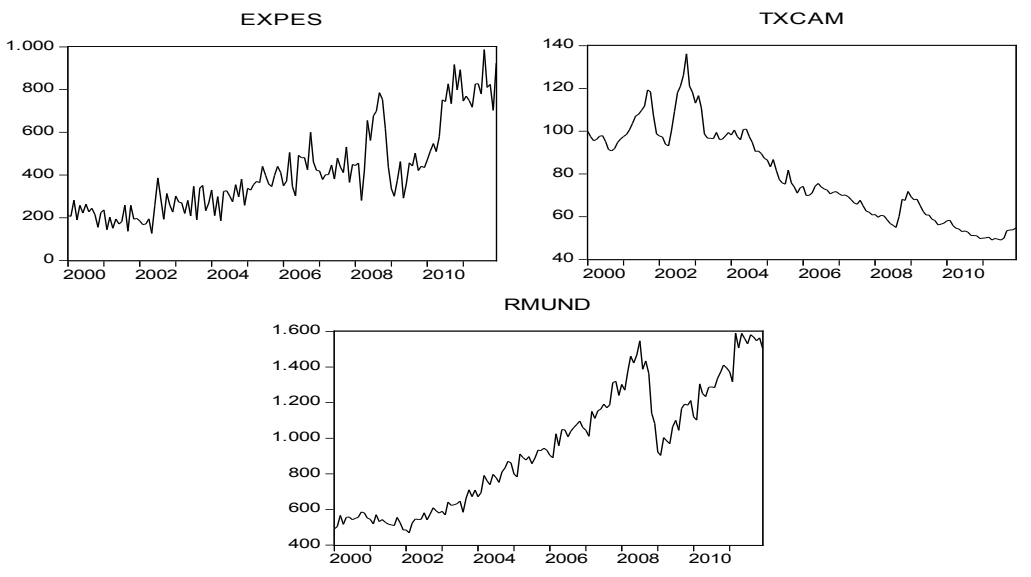

Fonte: Elaboração própria a partir dos dados da pesquisa.

\subsection{Testes de Raiz Unitária}

Antes de se realizarem as análises econométricas, vale lembrar que se testou a presença de sazonalidade nas séries pelo teste combinado para a presença de sazonalidade, identificável na rotina de dessazonalização X12 do US Census Bureau. Aquelas que apresentaram sazonalidade foram dessazonalizadas pelo mesmo método, a saber: EXPES e TXCAM. Além disso, todos os procedimentos econométricos foram realizados com as variáveis expressas em logaritmos naturais.

O primeiro passo na análise de séries temporais é verificar se elas são estacionárias. Se elas não forem estacionárias em nível, deve-se realizar algum procedimento para estacionarizá-las (em geral, aplica-se a primeira diferença nas mesmas, dado que a maioria das séries econômicas é I(1), ou seja, integradas de primeira ordem). Neste trabalho foram utilizados os seguintes testes de raiz unitária: Augmented Dickey-Fuller - ADF (DICKEY; FULLER, 1981); Phillips-Perron - PP (PHILLIPS; PERRON, 1988); e, Kwiatkowski-Phillips-Schmidt-Shin - KPSS (KWIATKOWSKI et al., 1992). ${ }^{9}$

Os resultados podem ser verificados na Tabela 4. Pela análise dos testes estabelecidos, verificou-se que as variáveis EXPES, TXCAM e RMUND mostraram-

9 Vale ressaltar que o teste KPSS é um teste assintótico, e que ele deve ser utilizado em complemento aos demais testes de raiz unitária (BUENO, 2011). Assim, as conclusões sobre a existência de raiz unitária foram feitas primeiramente tomando como base os testes $\mathrm{ADF}$ e PP, e, em caso de divergência entre os testes $\mathrm{ADF}$ e PP, utilizou-se o teste KPSS como critério de desempate. Como critério de desempate também foram analisados os gráficos e os correlogramas (funções de autocorrelação) das séries. 
-se não estacionárias em nível. Destaca-se que, aplicada a primeira diferença nas séries, elas se tornaram estacionárias. Ressalta-se que não existe um consenso na literatura no que se refere a trabalhar com as variáveis no modelo VAR em nível e/ ou em primeira diferença. Sims (1980) e Sims, Stock e Watson (1990), por exemplo, não veem maiores problemas em se trabalhar com variáveis estacionárias e não estacionárias em um modelo VAR.

Tabela 4 - Testes de raiz unitária para as variáveis em nível

\begin{tabular}{lllllll}
\hline Variável & ADF & K & PP & K & KPSS & K \\
\hline LEXPES_SA & $-0,467075^{\text {ns }}$ & 3 & $-2,306470^{\text {ns }}$ & 7 & $0,060966^{\text {ns }}$ & 8 \\
LTXCAM_SA & $-2,956557^{\text {ns }}$ & 1 & $-2,668055^{\text {ns }}$ & 3 & $0,148715^{* *}$ & 9 \\
LRMUND & $-2,761709^{\text {ns }}$ & 12 & $-3,090447^{* *}$ & 0 & $0,148621^{* *}$ & 9 \\
\hline
\end{tabular}

Fonte: Elaboração própria a partir dos dados da pesquisa.

Nota: 1 ) ** Significativo a 5\%, ${ }^{\text {ns }}$ Não significativo; 2) $\mathrm{K}$ = número de defasagens de cada teste para cada variável; 3) $\mathrm{L}$ = indica que as variáveis estão expressas em logaritmos; e, 4) $\mathrm{SA}=$ série dessazonalizada.

\subsection{Teste de Cointegração de Johansen}

Uma vez realizados os testes de raiz unitária, apresentam-se os testes de cointegração de Johansen. Na elaboração do teste é fundamental determinar o número de defasagens. Para isso, estimou-se um VAR irrestrito com as séries em nível, observando os critérios da razão de verossimilhança (LR), do erro de previsão final (FPE), de Akaike (AIC), de Schwarz (SC) e de Hannan-Quinn (HQ) para selecionar o número de defasagens a ser empregado. Os critérios SC e HQ sugeriram a utilização de uma defasagem para o modelo, conforme a Tabela 5. Entretanto, optou-se por trabalhar com duas defasagens, baseando-se nos critérios FPE e AIC, uma vez que o modelo com uma defasagem apresentou autocorrelação dos resíduos e heterocedasticidade.

Tabela 5 - Determinação do número de defasagens do modelo VAR

\begin{tabular}{|c|c|c|c|c|c|}
\hline Defasagem & LR & FPE & AIC & SC & HQ \\
\hline 0 & NA & $4,75 \mathrm{E}-05$ & $-1,442133$ & $-1,377884$ & $-1,416024$ \\
\hline 1 & 763,5045 & $1,67 \mathrm{E}-07$ & $-7,093905$ & $-6,836906^{*}$ & $-6,989467^{*}$ \\
\hline 2 & 25,61743 & $1,56 \mathrm{e}-07 *$ & $-7,160137^{*}$ & $-6,710389$ & $-6,977371$ \\
\hline 3 & 8,133275 & 1,67E-07 & $-7,092334$ & $-6,449836$ & $-6,831239$ \\
\hline 4 & $20,76528^{*}$ & 1,61E-07 & $-7,128804$ & $-6,293558$ & $-6,789381$ \\
\hline 5 & 15,89507 & 1,61E-07 & $-7,12891$ & $-6,100914$ & $-6,711159$ \\
\hline
\end{tabular}


conclusão.

\begin{tabular}{clllll}
\hline Defasagem & LR & FPE & AIC & SC & HQ \\
\hline 6 & 7,556083 & $1,73 \mathrm{E}-07$ & $-7,061139$ & $-5,840394$ & $-6,565059$ \\
7 & 12,15907 & $1,78 \mathrm{E}-07$ & $-7,035445$ & $-5,621951$ & $-6,461037$ \\
8 & 9,061108 & $1,88 \mathrm{E}-07$ & $-6,984724$ & $-5,37848$ & $-6,331987$ \\
\hline
\end{tabular}

Fonte: Elaboração própria a partir dos dados da pesquisa.

Nota: 1) * Indica a ordem selecionada pelo critério; e, 2) LR = razão de verossimilhança $(\mathrm{LR}), \mathrm{FPE}=$ erro de previsão final; $\mathrm{AIC}=$ Akaike, $\mathrm{SC}=$ Schwarz e HQ = Hannan-Quinn.

Nas Tabelas 6 e 7 são apresentados os testes de traço $\left(\lambda_{\text {trace }}\right)$ e máximo autovalor $\left(\lambda_{\max }\right)$. Como pode ser observado, ambos os testes revelaram a presença de apenas um vetor de cointegração, demonstrando a existência de uma relação de longo prazo entre as variáveis EXPES_SA, TXCAM_SA e RMUND.

Tabela 6 - Resultados do teste de traço

\begin{tabular}{cccc}
\hline $\begin{array}{c}\text { Hipótese nula } \\
\left(\boldsymbol{H}_{\mathbf{0}}\right)\end{array}$ & $\begin{array}{c}\text { Hipótese alternativa } \\
\left(\mathbf{H}_{\mathbf{1}}\right)\end{array}$ & $\lambda_{\text {trace }}$ & $\lambda_{\text {trace }}$ (crítico) \\
\hline$r=0$ & $r>0$ & 28,49924 & 27,06695 \\
$r \leq 1$ & $r>1$ & 9,196339 & 13,42878 \\
$r \leq 2$ & $r>2$ & 0,137962 & 2,705545 \\
\hline
\end{tabular}

Fonte: Elaboração própria a partir dos dados da pesquisa.

Tabela 7 - Resultados do teste de máximo autovalor

\begin{tabular}{cccc}
\hline $\begin{array}{c}\text { Hipótese nula } \\
\left(\boldsymbol{H}_{\mathbf{0}}\right)\end{array}$ & $\begin{array}{c}\text { Hipótese alternativa } \\
\left(\mathbf{H}_{\mathbf{1}}\right)\end{array}$ & $\lambda_{\max }$ & $\lambda_{\max }$ (crítico) \\
\hline$r=0$ & $r=1$ & 19,30290 & 18,89282 \\
$r=1$ & $r=2$ & 9,058377 & 12,29652 \\
$r=2$ & $r=3$ & 0,137962 & 2,705545 \\
\hline
\end{tabular}

Fonte: Elaboração própria a partir dos dados da pesquisa.

\subsection{Vetor de Correção de Erros (VECM)}

Determinada a relação de cointegração, o VECM foi estimado para estabelecer o comportamento dinâmico das exportações capixabas. Ressalta-se que, como o melhor VAR irrestrito é aquele com duas defasagens, o VECM foi trabalhado 
com uma defasagem. ${ }^{10}$ Os resultados demonstrados na Tabela 8 são relativos à equação de equilíbrio de longo prazo, que corresponde ao autovetor, normalizado para as exportações do Espírito Santo. Vale ressaltar que os sinais devem ser interpretados de maneira inversa.

Verifica-se que o coeficiente da taxa de câmbio não apresentou sinal de acordo com a teoria econômica, de encontro a condição de Marshall-Lerner. Esperava-se que a TXCAM_SA impactasse positivamente nas exportações capixabas. No entanto, isso corrobora o Gráfico 1, que demonstra que as variáveis EXPES e TXCAM caminharam, em geral, em direções opostas ao longo do período de janeiro de 2000 a dezembro de 2011 . Nesse período, o coeficiente de correlação de Pearson entre as duas variáveis foi de -0,795919 (forte correlação negativa). Vale ressaltar que tal variável revelou-se não significativa estatisticamente.

Entretanto, conforme esperado, a renda mundial afeta positivamente as exportações do Espírito Santo no longo prazo. O coeficiente estimado foi estatisticamente significativo, e mostra que um aumento da renda mundial de $1 \%$ acarreta em uma elevação de cerca de $0,96 \%$ nas exportações do estado. A elasticidade da renda mundial é, aproximadamente, três vezes maior que a elasticidade da taxa de câmbio. Este pode ser um indicativo do crescimento das exportações mesmo havendo uma queda da taxa de câmbio no período analisado. Nesse sentido, o crescimento da renda mundial e, consequentemente, da demanda mundial, faz com que as exportações não dependam tanto da taxa de câmbio. Além disso, é importante mencionar que a pauta de exportações capixaba é concentrada em commodities, especialmente o minério de ferro e o aço. Com o crescimento econômico dos BRICS, com destaque para a China, a demanda por commodities tem aumentado significantemente nos últimos anos, o que contribui para as exportações da economia espírito-santense.

Tabela 8 - Estimativa de longo prazo do vetor de cointegração

\begin{tabular}{cccc}
\hline LEXPORT_SA & LTXCAM_SA & LRMUND & CONSTANTE \\
\hline 1,000000 & 0,315944 & $-0,956199$ & $-0,788160$ \\
& $(0,30771)$ & $(0,22573)$ & \\
\hline
\end{tabular}

Fonte: Elaboração própria a partir dos dados da pesquisa.

Nota: 1) Os valores entre parênteses representam os erros-padrão das estimativas; 2) $L=$ indica que as variáveis estão expressas em logaritmos; e, 3) SA = série dessazonalizada.

E relação aos coeficientes de curto prazo, seus valores demonstram as velocidades de ajustamento das variáveis consideradas no modelo, em direção ao

10 O modelo apresentou todas as raízes do polinômio dentro do círculo unitário, satisfazendo a condição de estabilidade. Além disso, os resultados foram satisfatórios para não autocorrelação (utilizaram-se quatro defasagens). 
equilíbrio de longo prazo. Logo, um baixo valor do coeficiente revela que, diante de um desequilíbrio transitório (de curto prazo), a velocidade de ajuste é lenta em direção ao equilíbrio de longo prazo. Conforme apresentando na Tabela 9, no curto prazo, o coeficiente da variável exportações foi igual a, aproximadamente, 0,5292, o que revela que os desequilíbrios transitórios das exportações capixabas são corrigidos a uma velocidade de 52,92\%. Assim, para a variável exportações, esses desequilíbrios são corrigidos de forma relativamente rápida, o que não acontece para as variáveis taxa de câmbio e renda mundial.

Tabela 9 - Estimativa de curto prazo do vetor de cointegração

\begin{tabular}{ccc}
\hline DLEXPORT_SA & DLTXCAM_SA & DLRMUND \\
\hline$-0,529230$ & 0,001067 & $-0,001119$ \\
$(0,09974)$ & $(0,01865)$ & $(0,03200)$ \\
\hline
\end{tabular}

Fonte: Elaboração própria a partir dos dados da pesquisa.

Nota: 1) Os valores entre parênteses representam os erros-padrão das estimativas; 2) $\mathrm{D}=$ significa a primeira diferença da variável; 3) $\mathrm{L}$ = indica que as variáveis estão expressas em logaritmos; e, 4) SA = série dessazonalizada.

Finalizada a etapa de identificação e estimação do VECM, serão analisadas as funções de impulso-resposta. Ressalta-se que, antes de estimar as funções de impulso-resposta, é fundamental identificar o ordenamento de Cholesky do modelo VAR, um dos métodos mais populares para tal finalidade. Isso porque as funções de impulso-resposta são sensíveis à ordenação das variáveis. Esta pesquisa adotou, como método de ordenação das variáveis, o de informação a priori (teoria econômica, conhecimento do mercado, artigos, entre outros). ${ }^{11}$ A ordenação adotada foi: LRMUND, LTXCAM_SA e LEXPES_SA. Devido à importância da ordenação de Cholesky para a correta estimação das funções de impulso-resposta, tentaram-se outros ordenamentos (o que pode ser considerado um teste de robustez), que não alteraram significantemente tais funções.

No Gráfico 2 são demonstradas as funções de impulso-resposta para as exportações do Espírito Santo. Inicialmente, para exemplificar a análise de uma função de impulso-resposta, toma-se o caso do efeito da LTXCAM_SA sobre as exportações. Nota-se que uma elevação de um desvio-padrão na LTXCAM_SA causa um efeito positivo sobre as exportações somente no segundo mês após o choque, e mesmo assim de maneira relativamente baixa. Nos demais meses depois do cho-

11 Vale lembrar que vários autores brasileiros passaram a justificar a ordenação das variáveis em seus modelos com base no Teste de Causalidade de Granger (Block Exogeneity Wald Tests). No entanto, segundo Cavalcanti (2010), a identificação do ordenamento do modelo VAR através da causalidade Granger não seria apropriada, uma vez que a ordenação de Cholesky indica causalidade contemporânea entre as variáveis, ao passo que o teste de Granger refere-se à causalidade de precedência temporal. 
que, o que se verifica são reduções das exportações, contrário ao esperado pela teoria econômica. Em relação à variável LRMUND, observa-se que um choque na mesma leva a sucessivos aumentos nas exportações capixabas, que perpetuam pelos 12 meses considerados. Além disso, ao final do período de 12 meses, as exportações ficam bem acima do patamar inicial (antes do choque na LRMUND).

É importante mencionar que, novamente, a taxa de câmbio não se mostrou importante para as exportações do estado (no que se refere ao crescimento), sendo que a grande relevância da renda mundial parece compensar esse resultado não esperado. Isso pode ser corroborado pelo Gráfico 1 (item estatísticas descritivas e análise gráfica das variáveis), onde pode-se notar que as variáveis EXPES_SA e RMUND apresentam evolução muito semelhante, inclusive durante a crise do subprime.

Gráfico 2 - Funções de impulso-resposta para exportações capixabas

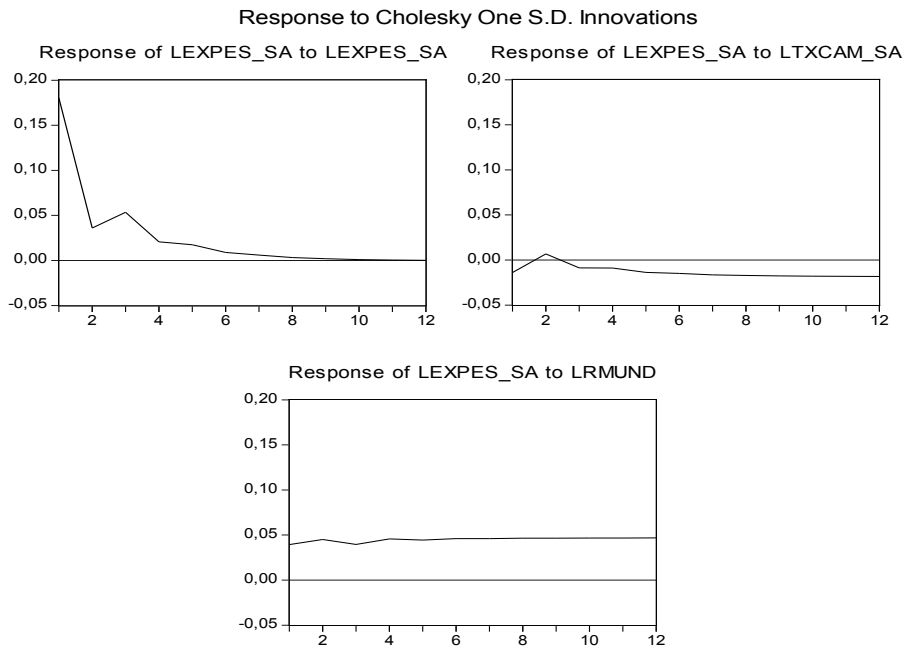

Fonte: Elaboração própria a partir dos dados da pesquisa.

Notas: 1) $\mathrm{L}=$ indica que as variáveis estão expressas em logaritmos; e, 2) SA = série dessazonalizada.

A metodologia VECM permite, em complemento a análise das funções de impulso-resposta, a realização do exercício de decomposição da variância (DV), com o intuito de verificar o poder explanatório de cada variável do modelo sobre as demais, por meio da decomposição da variância do erro de previsão. Aqui também se adotou o ordenamento de Cholesky: LRMUND, LTXCAM_SA e LEXPES_SA. Na Tabela 10 são apresentados os resultados da decomposição para as exportações do Espírito Santo. 
Tabela 10 - Decomposição histórica da variância dos erros de previsão das exportações do Espírito Santo

\begin{tabular}{ccccc}
\hline MÊS & ERRO-PADRÃO & LEXP_SA & LTXCAM_SA & LRMUND \\
\hline 1 & 0,184951 & 94,91210 & 0,563136 & 4,524766 \\
2 & 0,193845 & 89,85453 & 0,636616 & 9,508854 \\
3 & 0,205083 & 87,05208 & 0,748101 & 12,19982 \\
4 & 0,211301 & 82,96568 & 0,879928 & 16,15439 \\
5 & 0,217048 & 79,27210 & 1,230317 & 19,49759 \\
6 & 0,222556 & 75,55379 & 1,621533 & 22,82468 \\
7 & 0,227943 & 72,09282 & 2,067302 & 25,83987 \\
8 & 0,233284 & 68,84912 & 2,513418 & 28,63746 \\
9 & 0,238547 & 65,85088 & 2,951673 & 31,19745 \\
10 & 0,243736 & 63,07878 & 3,369370 & 33,55185 \\
11 & 0,248838 & 60,51878 & 3,763773 & 35,71744 \\
12 & 0,253853 & 58,15117 & 4,133330 & 37,71550 \\
\hline
\end{tabular}

Fonte: Elaboração própria a partir dos dados da pesquisa.

Notas: 1) $\mathrm{L}$ = indica que as variáveis estão expressas em logaritmos; e, 2) $\mathrm{SA}=$ série dessazonalizada.

Nota-se que os maiores percentuais de explicação do erro de previsão das exportações são decorrentes das próprias exportações. Verifica-se que, no período de análise, a renda mundial teve impacto fortemente superior a taxa de câmbio sobre o erro de previsão das exportações. Ao final de 12 meses, a taxa de câmbio explica $4,13 \%$ do erro de previsão, ao passo que a renda mundial explica 37,71\% desse erro. Ou seja, no decorrer dos 12 meses, o poder de explicação da renda mundial vai se tornando relativamente superior ao da taxa de câmbio, revelando novamente a importância do cenário internacional para as exportações do Espírito Santo.

\section{Considerações Finais}

O objetivo deste estudo foi estimar os impactos de choques na taxa de câmbio e na renda mundial sobre as exportações do Espírito Santo, utilizando a metodologia VAR/VECM. Realizou-se a análise de cointegração das variáveis, das funções impulso-resposta e da decomposição da variância dos erros de previsão.

No que se refere à análise de cointegração, observou-se que as variáveis EXPES, TXCAM e RMUND possuem um relacionamento de longo prazo, apresentando um vetor de cointegração. Nas estimativas de longo prazo do vetor de 
cointegração, a variável taxa de câmbio apresentou sinal contrário à teoria econômica. Já a variável renda mundial mostrou-se coerente com a teoria, apresentando grande elasticidade em relação às exportações. Quanto às estimativas de curto prazo do vetor de cointegração, para a variável exportações os desequilíbrios de curto prazo são corrigidos de forma relativamente rápida, o que não acontece para as variáveis taxa de câmbio e renda mundial.

A análise das funções de impulso-resposta demonstrou que: a) um choque na taxa de câmbio tem efeito positivo sobre as exportações somente no segundo mês após o choque. No restante do período analisado, de encontro ao esperado, os efeitos da taxa de câmbio foram negativos; b) choques na renda mundial impactam positivamente nas exportações durante todo o período de 12 meses, revelando a importância de tal variável para as exportações do Espírito Santo. Corroborando a relevância da renda mundial, pela análise da decomposição da variância, notou-se que a variância do erro de previsão das exportações capixabas é explicada, principalmente, pela renda mundial, tendo a taxa de câmbio poder explicativo relativamente baixo.

Vale mencionar que as variáveis utilizadas não são os únicos fatores que afetam as exportações. Fatores como logística, qualidade, competitividade, concorrência internacional, burocracia interna, entre outros, são de grande importância para se conseguir destaque no concorrido mercado internacional. Uma logística adequada, por exemplo, é fundamental para que os produtos cheguem aos mercados (países) demandantes, além do que a cadeia logística impacta diretamente no preço final dos produtos exportados e, consequentemente, na competitividade. Nesse contexto, o governo pode ter papel fundamental, proporcionando as bases para que as empresas de comércio exterior presentes ou que venham se instalar no estado do Espírito Santo sejam competitivas no cenário internacional. Para tanto, investimentos contínuos em infraestrutura de rodovias, portos, aeroportos, disponibilidade de crédito, desburocratização dos procedimentos para exportação, entre outros, são fundamentais.

Conforme verificado, a renda mundial e, consequentemente, o aquecimento da demanda mundial, são os principais determinantes das exportações capixabas. Apesar das crises internacionais vivenciadas nos últimos anos, as exportações do estado veem apresentado um bom desempenho, especialmente no que se refere às commodities. Destaca-se, também, que o aumento das exportações tem ocorrido mesmo em um cenário de queda da taxa de câmbio. Saber aproveitar esses momentos é de fundamental importância para que o estado do Espírito Santo se consolide cada vez mais como um forte player do setor de exportação.

Por fim, para estudos futuros, sugere-se a inclusão de outras variáveis no modelo, a fim de prever com maior robustez as oscilações das exportações capixabas. Recomenda-se, também, a comparação do poder de previsão da modelagem 
VAR/VECM com os modelos univariados. No mais, seria interessante analisar as exportações do Espírito Santo para alguns produtos, a fim de verificar se elas seguem o padrão das exportações agregadas (exportações totais), e até mesmo de comparar o comportamento das exportações do Espírito Santo com outros estados brasileiros.

\section{Referências}

ALVES, L. R. A.; BACCHI, M. R. P. Oferta de exportação de açúcar do Brasil. Revista de Economia e Sociologia Rural, Brasília, DF, v. 42, n. 1, p. 9-33, 2004.

BARROS, G. S. C.; BACCHI, M. R. P.; BURNQUIST, H. L. Estimação de equações de oferta de exportação de produtos agropecuários para o Brasil (1992/2000). Brasília: Ipea, 2002. (Texto para Discussão, 865).

BRASIL. Ministério do Desenvolvimento Indústria e Comércio Exterior. Secretaria do Comércio Exterior. Balança comercial: unidades da federação. 2012a. Disponível em: $<$ http://www.desenvolvimento.gov.br/sitio/interna/interna.php?area $=58 \mathrm{menu}=1076>$. Acesso em: 6 ago. 2012.

. Ministério do Desenvolvimento, Indústria e Comércio Exterior. Secretaria de Comércio Exterior. Outras estatísticas de comércio exterior. 2012b. Disponível em: <http://desenvolvimento. gov.br//sitio/interna/interna.php?area=5Emenu=608>. Acesso em: 10 ago. 2012.

BUENO, R. D. L. S. Econometria de séries temporais. 2. ed. São Paulo: Cengage Learning, 2011 .

CAMPBELL, J. Y.; PERRON, P. Pitfalls and opportunities: what macroeconomists should know about unit roots. In: BLANCHARD, O. J.; FISCHER, S. (Ed.). NBER Macroeconomics annual. Cambridge, CA: The MIT Press, 1991. p. 141-201.

CARVALHO, A.; DE NEGRI, J. A. Estimação de equações de importação e exportação de produtos agropecuários para o Brasil (1977/1998). Brasília: Ipea, 2000. (Texto para Discussão, 698).

CASTRO, A. S.; CAVALCANTI, M. A. F. H. Estimação de equações de exportação e importação para o Brasil: 1955/95. Pesquisa e Planejamento Econômico, Rio de Janeiro, v. 28, n. 1, p. 1-68, 1998.

CASTRO, A. S.; ROSSI JÚNIOR, J. L. Modelos de previsão para a exportação das principais commodities brasileiras. Rio de Janeiro: Ipea, 2000. (Texto para Discussão, 716).

CAVALCANTI, M. A. F. H. Identificação de modelos VAR e causalidade de Granger: uma nota de advertência. Economia Aplicada, v. 14, n. 2, p. 251-260, 2010.

CAVALCANTI, M. A. F. H.; RIBEIRO, M.A. As exportações no período 1977/96: desempenho e determinantes. Brasília: Ipea, 1998. (Texto para Discussão, 545).

DICKEY, D. A.; FULLER, W. A. Likelihood ratio statistics for autoregressive time series with a unit root. Econometrica, v. 49, n. 4, p. 1057-1073, 1981. 
ENGLE, R. F.; GRANGER, C. W. J. Cointegration and error correction: representation, estimation, and testing. Econometrica, v. 55, n. 2, p. 251-276. 1987.

HANSEN, H.; JUSELIUS, K. Cats in rats: cointegration analysis of time series. USA: Estima, 1995.

KWIATKOWSKI, D. et al. Testing the null hypothesis of stationarity against the alternative of unit root. Journal of Econometrics, v. 54, n. 1, p. 159-178. 1992.

MACKINNON, J. C.; HAUG, A. A.; MICHELIS, L. Numerical distribution functions of likelihood ratio tests for cointegration. Journal of Applied Econometrics, v. 14, p. 563-577, 1999.

MAGALHÃES, M. A.; TOSCANO, V. N. Grau de abertura para economia do Espírito Santo. Vitória: Instituto Jones dos Santos Neves, 2009.(Nota técnica, n. 8). Disponível em: <http:// www.ijsn.es.gov.br/Sitio/attachments/297_ijsn_nt08.pdf>. Acesso em: 6 ago. 2012.

MAIA, S. F. Determinantes das exportações agrícolas em cenário de macroeconomia aberta: abordagem por modelos de séries de tempo. In: ENCONTRO NACIONAL DE ECONOMIA DA ANPEC, 31., 2003, Porto Seguro. Anais... Porto Seguro: ANPEC, 2003. CD-ROM.

MIRANDA, S. H. G. Quantificação dos efeitos das barreiras não-tarifárias sobre as exportações brasileiras de carne bovina. 2001. 237 f. Tese (Doutorado em Economia Aplicada) - Escola Superior de Agricultura Luiz de Queiroz, Universidade de São Paulo, Piracicaba, SP, 2001.

MORAIS, I. A. C.; BARBOSA, A. E. Equações de oferta e demanda por exportações do setor de calçados, 1985/2003. Análise Econômica, Porto Alegre, v. 17, n. 1, p. 67-90. 2006.

PADRÃO, G. A.; PROFETA, G. A.; GOMES, M. F. M. Determinantes da exportação mineira de café. In: CONGRESSO DA SOCIEDADE BRASILEIRA DE ECONOMIA ADMINISTRAÇÃO E SOCIOLOGIA RURAL, 48., 2010, Campo Grande. Anais eletrônicos... Campo Grande: Sober, 2010. Disponível em: <http://www.sober.org.br/palestra/15/910.pdf>. Acesso em: 27 fev. 2011.

PHILLIPS, P. C. B.; PERRON, P. Testing for unit roots in time series regression. Biometrika, v. 75, n. 3, p. 335-346, 1988.

SAPIENZA, L. D. Análise do desempenho da balança comercial brasileira: estimações das elasticidades das funções da oferta de exportação e da demanda de importação (1980/2006). 2007. 88 f. Dissertação (Mestrado em Economia) - Programa de Pós-Graduação em Economia, Fundação Getúlio Vargas, São Paulo, 2007.

SILVA, E. K.; MAIA, S. F. As exportações brasileiras de café (1961-2001): uma análise usando vetores autoregressivos. In: CONGRESSO DA SOCIEDADE BRASILEIRA DE ECONOMIA ADMINISTRAÇÃO E SOCIOLOGIA RURAL, 41., 2003, Juiz de Fora. Anais eletrônicos... Juiz de Fora: Sober, 2003. Disponível em: <http://www.biblioteca.sebrae.com.br/bds/BDS.nsf/4 CAF1440336F023003256FF100605126/\$File/NT000A6EF2.pdf>. Acesso em: 25 fev. 2011.

SILVA, M. V. S. S.; BACCHI, M. R. P. B. Condicionantes das exportações brasileiras de açúcar bruto. Agricultura em São Paulo, São Paulo, v. 52, n. 2, p. 99-110. 2005.

SIMS, C. Macroeconomics and reality. Econometrica, v. 48, n. 1, p. 1-48, 1980. 
SIMS, C.; STOCK, J.; WATSON, M. Inference in linear time series models with some unit roots. Econometrica, v. 58, p. 113-144, 1990.

ZINI JÚNIOR, A. A. Funções de exportação e de importação para o Brasil. Pesquisa e Planejamento Econômico, Rio de Janeiro, v. 18, n. 3, p. 615-662, 1988.

Recebido em; 24/08/2012. Aceito em: 29/07/2013. 